\title{
Designing a Greenhouse Gas Emission Market for Mexico
}

\author{
David Cantala, Stephen McKnight, Jaume Sempere* \\ Centro de Estudios Económicos, El Colegio de México, Camino al Ajusco 20, 10740 México, D. F. \\ *Corresponding Author: jsempe@colmex.mx
}

Copyright (C) 2013 Horizon Research Publishing. All rights reserved.

\begin{abstract}
We analyze the design of a cap and trade scheme of greenhouse gas emissions for Mexico. We use existing economic theory and past experiences to analyze the key issues and problems typically encountered when designing cap and trade schemes. We also discuss the possible constraints for the integration of Mexico into a regional North American emissions market.
\end{abstract}

Keywords Cap and Trade, Market Design, Developing Countries

\section{Introduction}

Even though some developing countries are not subject to the restrictions imposed by the Kyoto Protocol, they still have a significant role to play in the reduction of global greenhouse gas emissions. While greenhouse gas emissions have stabilized in developed countries during $1990-2008$, such emissions have more than doubled in developing countries for the same period (Peters, et al. 2011). Indeed, a number of recent studies have found evidence of a sizeable transfer of emissions from developed to developing countries due to shifting international trade patterns. 1 In general, developed countries have been found to be net emission importers, whereas developing countries are typically net exporters of emissions.

In this paper we analyze the key issues in designing a greenhouse gas emission market for Mexico, a country that is not restricted by the Kyoto Protocol (even though it is a signatory of the Protocol). The case of Mexico is of particular interest for a number of reasons. Unlike many developing countries, Mexico has experience in designing, implementing, and regulating cap and trade mechanisms. Secondly, Mexico is a member of NAFTA, the world's largest regional trading bloc (in terms of total member GDP).2 Furthermore, as shown by Table 1, in 2010 Mexico was the 4th largest producer of greenhouse gasses of the

1 See, for example, Weber and Matthews (2007), Weber, et al. (2008), Hertwich and Peters (2009), Baiocchi and Minx (2010), Wiedmann, et al. (2010), Peters, et al. (2011).

2 The North American Free Trade Agreement was signed by Canada, Mexico and the United States in 1994 and is the first regional free trade area comprised of both developed and developing countries.
OECD (after the US, Japan and Germany), emitting approximately 748.25 million tonnes of $\mathrm{CO} 2$ equivalent. On the other hand, Graph 1 shows an increasing trend in Greenhouse gas emissions. Finally, starting in 2012 the Mexican government has launched the special program for climate change: Programa Especial de Cambio Climático (PECC) 2009-2012. The quantitative objective of the PECC is to achieve by 2050 a $50 \%$ reduction in greenhouse gas emissions (with respect to the emission level in 2000). Furthermore, Mexico is a signatory of the Copenhagen Accord and aims to reduce its greenhouse gas emissions by up to $30 \%$ (with respect to the business as usual scenario) by 2020.

One of the main instruments proposed by the PECC is a cap and trade scheme, whereby the Mexican regulator issues emission permits that could potentially be traded internationally. Initially, the PECC proposes to create a cap and trade scheme for state-owned energy producers, with the long-run objective of developing an integrated North American greenhouse gas emissions market.

Table 1. Total Greenhouse Gas (GHG)Emissions - Country Rankings in the OECD

\begin{tabular}{|c|c|c|}
\hline Country & $\begin{array}{c}\text { Latest Year } \\
\text { Available }\end{array}$ & $\begin{array}{c}\text { Total GHG } \\
\text { Emissions } \dagger\end{array}$ \\
\hline United States & 2011 & 6665.7 \\
\hline Japan & 2011 & 1307.72 \\
\hline Germany & 2011 & 943.51 \\
\hline Mexico & 2010 & 748.25 \\
\hline Canada & 2011 & 701.79 \\
\hline United Kingdom & 2011 & 556.45 \\
\hline Australia & 2011 & 552.28 \\
\hline France & 2011 & 491.49 \\
\hline Italy & 2011 & 488.79 \\
\hline Turkey & 2011 & 422.41 \\
\hline
\end{tabular}

$\dagger$ Million tonnes of $\mathrm{CO}_{2}$ equivalent

Source:OECD.StatExtracts

Given that Mexico is not restricted by the Kyoto Protocol, the reduction in emission levels could be partially or totally 
financed by Protocol countries. If emission permits issued by Mexico are purchased by foreign firms, the economic cost of the emission reduction rests with foreign countries. Naturally, these countries will only allow domestic firms to purchase Mexican emission permits if the cap and trade scheme satisfies several requirements. Of particular importance is the need for credible agencies to certify the compliance of Mexican producers with the regulations, since otherwise, the cap imposes no effective constraint on Mexican emission levels.

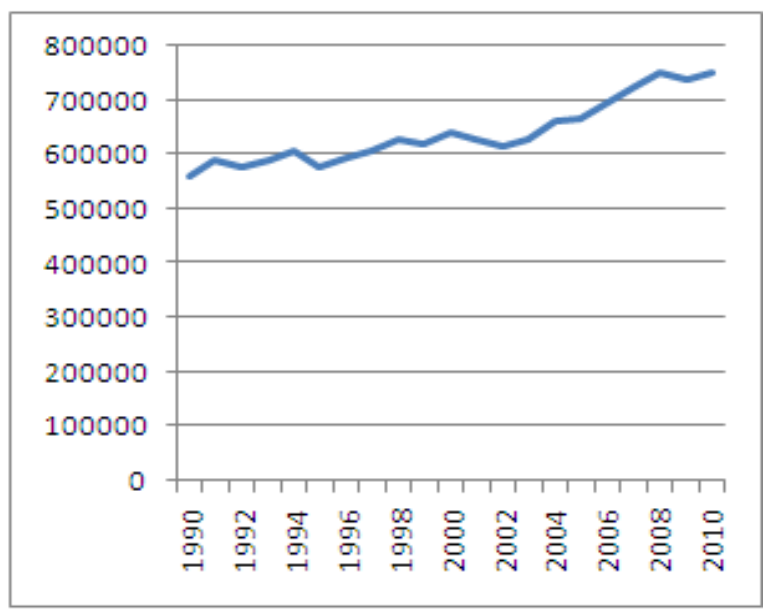

Graph 1. Mexico:Greenhouse gas emissions

If Mexico decides to introduce an emissions reduction program, important questions arise not only in terms of its monitoring, but also relating to the specific design of the cap and trade scheme, and its potential economic consequences. The objective of this paper is to critically examine the individual components of a cap and trade market scheme, and identify the key issues and challenges faced by the Mexican authorities in its possible design. We also analyze the desirability of a regional North American greenhouse gas emissions market from the perspective of Mexico.

This research complements the descriptive report by Burtraw, et al. (2010) which outlines a number of possible strategies to reduce greenhouse emissions in Mexico. While they also consider the creation of a cap and trade program for regulated sectors, our paper, instead, focuses on market design issues of implementing such a program.

The remaining sections are as follows. Section 2 critically evaluates the design of a cap and trade scheme to reduce emissions in Mexico. Section 3 gives a brief summary of previous cap and trade experiences in Mexico and in the US and Canada, and considers the potential economic costs and benefits of creating a regional North American emission permits market. Finally, the key conclusions and recommendations from this study are summarized in Section 4.

\section{Designing a Cap and Trade Mechanism for Mexico}

Despite its theoretical benefits and some good empirical experiences (e.g. the market for acid rain in the $\mathrm{US}^{3}$ ), cap and trade mechanisms face a number of practical difficulties. First, the implementation of the emission-level target cannot be taken for granted and, instead, has to be imposed effectively by the system of law administration. It is also necessary to establish an accurate measurement system to detect emission levels by all firms regulated by the scheme. In order to ensure that the measurement system is not altered, the establishment of appropriate auditing standards is also required. Finally, it is imperative that the system of law administration can impose fines on individual firms for cases of non-compliance. In summary, it is necessary to have an institutional system strong enough to guarantee that all firms comply with the regulation. This will certainly be a necessary condition for third parties before they purchase Mexican emission permits, which is crucial if Mexico hopes to at least partially finance its emission reductions using overseas investment. Mexico is current ranked at number 105 in the world in terms of the Corruption Perception Index 2012 created by Transparency International. This suggests that additional efforts will have to be done in order to ensure the internationally credibility of the regulation.

Even with an effective institutional system there is however no guarantee that the emissions market will work either efficiently, or as anticipated. As shown by Figure 1, there are four key elements relating to the market design of cap and trade mechanisms that will ultimately determine the success or failure of the scheme. The first element relates to the initial allocation of permits. The second element is concerned with the issue of who is allowed to participate in the market. The third element considers the rules of permit exchange. That is, the mechanism has to decide between permitting bilateral trade, trade in centralized markets, or if all types of exchange are possible. The final key element relates to the time durability of the emission permit. We discuss each of these four elements in detail below.

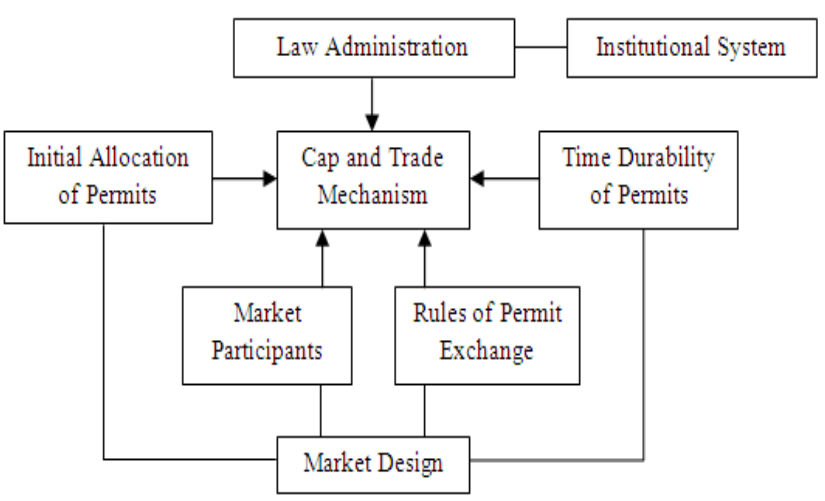

Figure 1. Key components in the design of cap and trade mechanisms

A final issue that is beyond the scope of this paper relates to the setting of the cap. In many countries the reduction of emissions is achieved using a variety of instruments, with the

${ }^{3}$ For instance, see Joscow, Schmalensee, and Bailey (1998). 
cap and trade mechanism being only one of them. While the tightness of the cap and the sectors involved are ultimately a political economy decision, this will have an impact on the tradability of the emission permits.

\subsection{Initial Allocation of Permits}

The initial allocation of permits can have important redistributive consequences (not only between production sectors, but also among consumers and firms) and consequences for the efficiency of the final allocation. ${ }^{4}$ In practice, the initial allocation can either be sold or allocated gratuitously. If the permits are to be sold, the orthodox way is through an auction mechanism. However, if the emission permits are gratuitous, they are generally allocated in proportion to historical emissions (so-called, grandfathering). Grandfathering has the advantage over auctions in that its political cost is lower. If the initial allocation of permits has to be purchased by auction, firms must absorb the full burden or cost of the regulation (although they can in principle pass some of this additional cost onto the final consumer through higher prices). In this case firms have a clear incentive to lobby against the regulation. It is well known from the theory of interest groups that the formation of lobbying groups are more likely to occur when the market has few members and the potential loss is high. ${ }^{5}$ In the case of environmental regulation, lobbying groups are likely to emerge when the number of firms subjected to the regulation is small, and the cost imposed by the regulation is large. Clearly, the emergence of interest groups elevates significantly the political cost of introducing the environmental regulation.

However, a trade-off arises as public revenue can be raised (that could, for example, be used to reduce the tax burden on individuals) if emission permits are auctioned instead of allocated gratuitously ${ }^{6}$. Therefore, one can view the non-auctioning of emission permits as equivalent to a subsidy from taxpayers to the regulated firms. Furthermore, it is well documented from economic theory that the auction mechanism, if well designed, would result in firms with the highest abatement costs purchasing the most permits.

One criticism of the European emission trading scheme has been that the vast majority of emission permits were initially allocated gratuitously (only $4 \%$ was allocated by auction). From the above discussion, this can be interpreted as a subsidy from European taxpayers to the regulated firms. For the next trading period it is envisaged that at least $50 \%$ of the emission permits should be allocated through auction. However, there are some economic sectors that will be exempt from the auctioning process, and consequently will continue to receive emission permits without cost. The

\footnotetext{
${ }^{4}$ See Burguet and Sempere (2010) for further details.

${ }^{5}$ See Schneider (2012) for a detailed discussion on the effects of the size of interest groups on lobbying.

${ }^{6}$ In fact, auctioning permits could be seen as a compensatory mechanism as part of the revenues received can be used, through appropriate tax breaks or rebates, to help offset (partially or fully) the negative effect of pollution on consumers (for more discussion on this issue see Shammin and Bullard, 2009).
}

justification for this exception is based on the idea of strategic sectors. A strategic sector relates to whether the regulation would create a sufficient incentive within the sector for firms to reallocate to a non-Kyoto participant in order to avoid paying the associated permit cost. The minimization of this carbon leakage is a central issue in the design of cap and trade schemes. ${ }^{7}$

The most important sectors subject to potential emissions regulation in Mexico are the electricity, oil and gas sectors. While these sectors are typically considered strategic, the potential carbon leakage effects are unimportant in this case, since the vast majority of these industries are state-owned. However, for private companies subjected to the regulation the cost represented by an auction mechanism could be sizable. In order to minimize carbon leakage one should evaluate the impact of the initial permit cost on firm localization and sensitivity to the regulation before implementing the auctioning of permits. This might be especially important for the Maquiladora sector and the Mexican automobile industry, where Mexico is the largest North American auto-producing nation. For Mexico, the integration into a regional North America emissions market would help to reduce the carbon leakage effects within the NAFTA area.

\subsection{Market Participants}

An important part in the design of any market relates to the agents that are allowed to participate in it. For cap and trade schemes, one possibility is to only allow trading among the firms regulated by the scheme. In this case, firms purchase the permits with the sole purpose of reducing abatement efforts. An alternative option is to open the market to other participants who cannot directly use the emission permits. This has the advantage of widening the market, since the over-restriction of participants may result in too thin a market, whereby potential traders are unable to find a match. However, the disadvantage of market widening is that participants may enter the market for speculative reasons, which can produce permit prices that are not efficient. With inefficient permit prices, the market fails to exert the required incentives on regulated firms and efficient emission reduction cannot be achieved.

Given the sectors established in the PECC, one of the main problems in designing an emissions trading market for Mexico is the likelihood of too few market participants. Therefore, unless the emissions market is opened up, it would be too thin and hencequite possibly uncompetitive. In addition, the sectors potentially subject to regulation are such that it might be difficult for these firms to reach cost efficiency, given the constraint imposed by the size of domestic market. Therefore, the integration into a larger international market appears to be a necessary condition for a

\footnotetext{
${ }^{7}$ A continued criticism of the European scheme relates to whether the strategic sector framework employed by the European Union accurately captures the notion of probable carbon leakage or not. For an empirical analysis based on interviewing managers see Anderson, et al. (2010).
} 
well-functioning permit market in Mexico.

\subsection{Type of Trade}

In market design, the rules of exchange (i.e. trade) need to be devised. Trade can either be bilateral and decentralized (i.e. each part has to find a counterpart for a trade to take place), or alternatively it can be realized in exchange markets in which all parts can meet to purchase or sell permits. The latter are generally characterized as being more informative and liquid, consequently requiring the presence of compensatory mechanisms to guarantee that all transactions can be made. Bilateral trade instead allows for more flexibility in the form of the exchange contracts.

The minimization of aggregate emission abatement costs requires that trading prices are not too disperse (in other words the trading prices are approximately unique). If bilateral trade prevails there is nothing in the market mechanism to ensure the emergence of a unique price for the emission permit. In this case the regulator has an important role to play in designing devices to prevent too much dispersion of trading prices.

Data from the European Climate Exchange suggest that most of the transactions in European emission allowances are over-the-counter (i.e. trade is bilateral), even though trade in exchange markets is possible. Finance theory (e.g. Seppi, 1990) shows that the amount of over-the-counter trading crucially depends on both the degree of private information of the investor, and the information sensitiveness of the asset. Given the prevalence of over-the-counter transactions in European emission allowances it appears that these two factors have not been very significant. However, the existence of exchange markets can also be important for uninformed traders to be able to take advantage from over-the-counter trading. Therefore, it seems that a well-functioning emission permits markets requires the coexistence of both types of exchanges.

\subsection{Time Durability of the Permit}

The final element of designing an emission market, concerns the time durability of the emission permit. In many practical cases the emission permit can be used during an interval of several years, thereby enabling the permit holder greater flexibility over abatement activities planning, and thus, for greater cost efficiency. In any case, given the need to trade permits internationally, the time durability of Mexican permits must be comparable to the emission permits of other countries. Therefore, we do not envisage the time durability of permits to be an important issue for Mexico.

\section{A regional North American Emission Permits Market}

\subsection{Cap and Trade Experiences of Mexico}

Unlike many developing countries, Mexico has experience in using cap and trade mechanisms. The most important of these relates to the mechanism implemented by PEMEX, the state-owned oil company, from 2001 to $2005 .{ }^{8}$ After a measurement and quantification phase, PEMEX proposed to reduce the emission of gasses by $1 \%$ per annum from the 1999 emission baseline. In order to achieve this reduction, PEMEX created an internal emissions market in which the market participants were comprised of 25 business units of the firm. Specifically, the market was a cap and trade mechanism that, in the first stage, assigned permits to each of the business units (one permit was equivalent to 1 metric tonne of carbon). Each business unit had to balance permits against emissions. In the case a business unit ended with more permit rights than emissions, the corresponding permits could be sold to other business units. Prices were negotiated through a computerized mechanism that registered transactions between business units, and to avoid price manipulations all transactions were carried out anonymously.

Given the perceived success of this mechanism, the PECC proposes to use a cap and trade scheme to reduce Mexico's greenhouse gas emission levels. Yet there are two fundamental differences between the PECC proposals and the PEMEX mechanism. The mechanism of the latter was established to reduce emissions of one individual firm. Furthermore, an integral part of the PECC proposals is the creation of emission permits that can be traded internationally.

\subsection{Cap and Trade Experiences in the US and Canada}

The United States, which signed but never ratified the Kyoto Protocol, has seen several legislative efforts to address GHG emissions. An attempt to establish an economy wide emissions trading program was the American Clean Energy and Security Act in 2009 (known as the Waxman-Markey bill). The Waxman-Markey bill would have established an economy-wide emissions trading program. But even though the U.S. House of Representatives passed it, the U.S.Senate never approved it. However, despite the absence of a nationwide system, several regions had already put in place or developed plans to implement their own GHG trading programs. Here we only mention them in brief (for details on a variety of U.S. emissions trading proposals, see Aldy, Pizer, and Raini, 2012).

In 2005, seven northeastern states in the United States agreed to an emissions trading program. Known as the Regional Greenhouse Gas Initiative, this program only covers large electricity generators, and nearly 100 percent of allowances are auctioned. A second U.S.-based emissions trading system began in California in 2013. While Arizona, California, New Mexico, Oregon, and Washington initiated

${ }^{8}$ For a detailed description of this mechanism see Gómez (2004). The mechanism was ultimately replaced by four other projects under the so-called Clean Development Mechanism, which is validated by the UN Framework Convention on Climate Change (UNFCCC). 
the Western Climate Initiative (WCI) in 2007, later adding Utah and Montana as well as the Canadian provinces of British Columbia, Ontario, Manitoba, and Quebec, no WCI states in the U.S. other than California have implemented an emissions trading program. California's program will initially cover the power sector and large industrial sources, accounting for roughly 37 percent of the state's GHG emissions, and aims to expand to cover 85 percent by 2015 , including transportation fuels.

A third regional agreement, the Midwestern Greenhouse Gas Reduction Accord (MGGRA), was signed in 2007. The accord was to function like the WCI, helping its members establish programs by 2012. In 2010, MGGRA released a detailed model rule for member states to adapt and use. The proposal covered the power sector, major industrial emitters, and transportation fuel distributors, with most allowances being allocated free of charge at the discretion of member states. Despite the MGGRA's progress, political and economic reasons ended the effort in early 2011.

Canada ratified the Kyoto Protocol in 2002 but never passed comprehensive legislation to regulate emissions. $\mathrm{CO} 2$ emissions exceeded their targets, and Canada withdrew from the Kyoto Protocol in 2011. Nonetheless, several provinces have made efforts to reduce GHG emissions. Quebec is currently on track to implement a GHG emissions trading program starting in 2013. The program will apply to industrial sources. Quebec developed the system using provisions developed under the WCI, allowing it to link with California. British Columbia, Manitoba, and Ontario, also WCI members, plan to adopt trading programs in the future but have not yet specified dates. The province of Alberta has adopted an internal program based on reducing energy intensity for large emitters, which allows some trade of allowances either between emitters or with the province. Most allowances are allocated freely to emitters, and, as of 2010, the program covered 97 facilities that accounted for roughly 50 percent of Alberta's GHG emissions.

\subsection{Economic Integration of a Mexican Cap and Trade Program with the Regional Programs in the US and Canada}

The discussion of section 2 suggested that the success of any emissions market in Mexico would require its integration into a larger and more competitive international emissions market. One natural possibility would be the creation of a regional North American emissions market or the integration of the Mexican market with one of the U.S. regional markets. Given its proximity, one possibility is the integration with the WCI. However, the implementation of a regional permits market can generate additional problems. When a regional market exists, one problem that can arise relates to heterogeneous regulations among the participant members. In the European emission system this created a distortion in the market, such that the value of the emission permits for regulated firms differed across member countries. ${ }^{9}$ We believe that the homogenization of environmental regulations will be a key feature in any future North American emissions market. That is, Mexico's integration into the market developed by the WCI would require the use of provisions developed under the WCI. The by-product of this for Mexico will be the need to effectively guarantee compliance with higher standards of environmental regulations. This will impose additional restrictions on Mexican firms and on the Mexican economy as a whole.

While the need for homogeneity in environmental regulations is clear, it will also be desirable to impose homogeneity of environmental policies in the creation of any North American emissions market. For countries bounded by free trade agreements like NAFTA, there is an incentive to relax environmental standards to increase the competitive advantage of domestic firms. In a regional emissions market, such incentives are further reinforced with heterogeneous members. For example, by issuing more permits than what is environmentally desirable, a country can sell these permits on the regional market. Without further restrictions, this implies that a participant country can effectively sell a low abatement cost permit at the international permit price, thereby receiving a net transfer from the other participants in the regional bloc. A moral hazard problem can arise as national regulators know better the cost for their national firms imposed by the regulation. Moral hazard is not a problem for Clean Development Mechanism projects, since it is easy to verify the actual emission reduction, because each project is individually certified.

Furthermore, unlike the European emissions market, there are reasons to believe that any North American equivalent will face additional efficiency concerns. Firstly, with the absence of a common currency, the purchasing power value of emission permits will vary across the regional bloc, due to exchange rate fluctuations. This could have important implications for efficiency. Secondly, the market power of the United States is likely to be large within any regional North American market. Copeland and Taylor (2005) and Burguet and Sempere (2010) study the impact of market power on international emission permits. Copeland and Taylor (2005) show that international trade in emission permits can have a non-negligible impact on the international terms of trade for commodities. This arises because a large country trading emission permits affects both the international prices of the permits and the prices of the goods themselves. Since emission permits are inputs for firms across the trading bloc, their trade has an impact on commodity markets. Burguet and Sempere (2010) show that terms of trade effects can have adverse consequences for the efficiency of the final allocation of emission permits. Overall the correct functioning of the regional emissions market is not guaranteed in the presence of a large country with market power.

${ }^{9}$ For further details, see Ellerman, et al. (2007). 


\section{Concluding Remarks: Some Lessons for Developing Countries}

Potentially, cap and trade schemes are a powerful tool to reduce greenhouse gas emissions. However, in order to reach this environmental objective at minimum cost, the working mechanism of the emission market has to be designed carefully.

In the case of Mexicothere are a number of important reasons why an emission market could fail. We have raised concerns over the possible carbon leakage effects of the regulation for private firms, and the emergence of speculators which will make it difficult to reach an efficient final assignment of rights, especially in a thin market. Of particular concern, relates to the treatment of state-owned industries, where the initial emission permits are likely to be allocated gratuitously, and other distortions in industrial markets that are not generally present in developed countries.

A key challenge faced by many developing countries is ensuring that there are sufficient participants in the emission trading market. If the number of firms is relatively low, there will be insufficient domestic competition within the market. A possible consequence of this is high variability in prices, which will not reflect the true cost of emission reduction. In this sense, outside competition is desirable. Such competition, however, will generate incentives for developing countries to assign initial permits with the objective to protect domestic firms. This distortion, in turn, could result in too many emission permits being issued, at too low a price. This moral hazard problem does not appear in existing Certified Emission Reductions markets, where the individual evaluation of projects is required.

The integration with larger markets also has an additional advantage: by generating sufficient scale for the profitable emergence of exchange markets, this helps facilitate bilateral transactions by providing reference prices. Such exchange markets already exist in developed countries and market integration would potentially enable the exchange of allowances issued by developing countries.

In conclusion, there are a number of potential problems in the design of cap and trade mechanisms for developing countries. One possible solution is the integration of developing markets into larger regional emission blocs. However, for regional permit markets to function optimally, an important requirement will be the homogenization of environmental regulations among participant countries.

\section{Acknowledgements}

Sempere gratefully acknowledges research support from a Marie Curie Grant financed by the European Commission under contract PERG07-GA-2010-268238. The comments of an anonymous referee are gratefully acknowledged.

\section{REFERENCES}

[1] Anderson, B., Leib, J., Martin, R., Muûls, M., de Preux, L. and Wagner, U. (2010), "Climate Change Policy and Business in Europe -Evidence from Interviewing Managers", Center for Economic Performance Discussion Paper, London School of Economics, in press.

[2] Baiocchi, G., Minx, J.C. (2010), "Understanding Changes in the UK's $\mathrm{CO}_{2}$ Emissions: A Global Perspective", Environmental Science and Technology 44, 1177-1184.

[3] Burguet, R. and Sempere, J. (2010), "Trade of Permits for Greenhouse Gas Emissions: Bilateral Trade Need Not be the Answer", Environmental and Resource Economics 56, 495-509.

[4] Burtraw, D., Kopp, R., Morgenstern, R., Morris, D., and Topping, E. (2010), "Feasibility Assessment of a Carbon Cap-and-Trade System for Mexico", RFF Report July 2010, Resources for the Future.

[5] Copeland, B., and Taylor, S. (2005), "Free Trade and Global Warming: A trade theory view of the Kyoto Protocol", Journal of Environmental Economics and Management 49, 205-234.

[6] Duflo, E., Greenstone, M., Pande, R. and Ryan, N. (2010), "Towards an Emissions Trading Scheme for Air Pollutants in India", Center for Energy and Environmental Policy Research working paper 10-011, MIT Energy initiative and Sloan School of Management, MIT.

[7] Ellerman, A.D., Buchner, B. and Carraro, C. (eds.) (2007), Allocations in the European Emissions Trading Scheme: Rights, Rents and Fairness, Cambridge University Press.

[8] Gómez, Ávila, S. (2004), "Mercado interno de permisos de emisiones de carbono. Estudio de Caso, PEMEX", en Martínez, J. y Fernández, A. (compiladores), Cambio Climático: Una visión desde México, Secretaría de Medio Ambiente, Instituto Nacional de Ecología.

[9] Hertwich, E.G., and Peters, G.P. (2009), "Carbon Footprint of Nations: A Global, Trade-Linked Analysis", Environmental Science and Technology 43, 6414-6420.

[10] Joscow, P., Schmalensee, R. and Bailey, E. (1998), "The Market for

[11] Sulfur Dioxide Emissions", American Economic Review 88, 669-685.

[12] Newell, R.G., Pizer, W.A., and Raimi, D. (2012), "Carbon Markets: Past, Present, and Future", Resources for the Future D.P. $12-51$

[13] Peters, G.P., Minx, J.C., Weber, C.L., and Edenhofer, O. (2011), "Growth in Emission Transfers via International Trade from 1990 to 2008", Proceedings of the National Academy of Sciences, doi: 10.1073/pnas.1006388108.

[14] Shammin, M. and Bullard, C., 2009. "Impact of Cap-and-trade Policies for Reducing Greenhouse Gas Emissions on U.S. Households". Ecological Economics 68: 2432-2438

[15] Schneider, M. (2012), "Interest-Group Size and Legislative Lobbying”, Mimeo, CER-ETH Zurich.

[16] Seppi, D. J. (1990), "Equilibrium Block Trading and 
Asymmetric Information,” Journal of Finance 45, 73-94.

[17] Weber, C.L., and Matthews, H.S. (2007), "Embodied Environmental Emissions in U.S. International Trade 1997-2004", Environmental Science and Technology 41, 4875-4881.

[18] Weber, C.L., Peters, G.P., Guan, D., and Hubacek, K. (2008),
"The Contribution of Chinese Exports to Climate Change", Energy Policy 36, 3572-3577.

[19] Wiedmann, T., Wood, R., Minx, J.C., Lenzen, M., Guan, D., and Harris, R. (2010), "A Carbon Footprint Time Series of the UK: Results from a Multi-Region Input-Output Model”, Economic Systems Research 22, 19-42. 